\title{
A Residential Energy Management System with Offline Population-Based Optimization
}

\author{
João Soares, Fernando Lezama, Sérgio Ramos, Zita Vale, André Lopes \\ GECAD - Research Group on Intelligent Engineering and Computing for Advanced Innovation and Development \\ Polytechnic of Porto, Porto, Portugal \\ \{joaps,flzcl,scr,zav,1151657\}@ isep.ipp.pt
}

\begin{abstract}
Expectable improvements in battery technology and lower prices will certainly contribute to increase the interest in residential energy storage systems in the near future. The installment of photovoltaic panels and the use of energy storage systems will help to reduce power losses in distribution and transmission power grid and increase network availability, and consequently, to reduce the dependency on the use of fossil fuels. The paper presents a light implementation of residential energy management system that integrates photovoltaic generation, an energy storage system and an electric vehicle. The goal of the system is to reduce the costs of electric consumer energy bill. The effectiveness of the system is verified through its application in several scenarios for the Portuguese context. An offline population-based algorithm, namely differential evolution method is used to adjust the objective function for the online control of the energy devices in the residential house.
\end{abstract}

Index Terms-Differential evolution, energy management system, energy costs, energy storage, electric vehicle, photovoltaic.

\section{NOMENCLATURE}

$\Delta t$

Time in hours of each period ' $\mathrm{t}$ ' (e.g., $15 \mathrm{~min}$. (0.25), 30 min. (0.5))

$B C E \quad$ Battery Charge Efficiency (\%)

EVCE EV Charge Efficiency (\%)

$B D E \quad$ Battery Discharge Efficiency (\%)

EVDE EV Discharge Efficiency (\%)

$E_{B}^{\text {init }}(t) \quad$ Energy in the battery at the beginning of period ' $\mathrm{t}$ ' (Wh)

$E_{E V}^{\text {init }}(t) \quad$ Energy in the EV at the beginning of period ' $\mathrm{t}$ ' $(\mathrm{Wh})$

$E_{B}^{\max } \quad$ Maximum energy the battery can store (Wh)

$E_{E V}^{\max } \quad$ Maximum energy the EV can store (Wh)

$E_{B}^{\min } \quad$ Minimum allowed energy in the battery (Wh)
$E_{E V}^{\min }(t) \quad$ Minimum allowed energy in vehicle at the end of the period ' $t$ ' (Wh)

$P_{\text {load }}(t) \quad$ Power consumed by the residence in period 't' (W)

$P_{c h B}(t) \quad$ Battery charge power in period 't' $(\mathrm{W})$

$P_{c h E V}(t) \quad$ EV charge power in period ' $\mathrm{t}$ ' (W)

$P_{\text {disB }}(t) \quad$ Requested power of the battery in period ' $\mathrm{t}$ ' (W)

$P_{\text {disEV }}(t)$ Power requested from EV in period ' $\mathrm{t}$ ' (W)

$P_{B}^{\max } \quad$ Maximum power for charge/discharge of battery (W)

$P_{\text {grid }}^{\max } \quad$ Maximum power that can be requested from the grid (W)

$P_{E V}^{\max } \quad$ Maximum power for charge/discharge of the EV (W)

$P_{p v}(t) \quad$ PV production of the period ' $\mathrm{t}$ ' (W)

$P_{\text {grid }}(t)$ requested power from the grid in period ' $t$ ' $(\mathrm{W})$

$P_{\text {sold }}(t) \quad$ Power sold to the grid at the 't' period (W)

$X_{a b s E V}(t)$ binary variable that indicates whether the EV is absent

$X_{c h B}(t)$ binary variable that indicates whether the battery is charging in period ' $\mathrm{t}$ '

$X_{c h E V}(t)$ binary variable indicating whether the EV is charging in period ' $t$ '

$X_{\text {disB }}(t)$ binary variable that indicates whether the battery is discharging in the period ' $\mathrm{t}$ '

$X_{\text {disEV }}(t)$ binary variable indicating whether the EV is discharging in the period ' $\mathrm{t}$ '

$\lambda_{c h B}(t) \quad$ Weight of the portion related to battery charge in period ' $\mathrm{t}$ '

$\lambda_{\text {chEV }}(t)$ Weight of the portion related to EV charge in period ' $t$ '

$\lambda_{\text {disB }}(t) \quad$ Weight of the portion related to the battery discharge in period ' $t$ '
The present work has been developed under the EUREKA - ITEA2 Project FUSE-IT (ITEA-13023), Project GREEDI (ANI|P2020 17822), and has received funding from FEDER Funds through COMPETE program and from National Funds through FCT under the project UID/EEA/00760/2013. 


$$
\begin{array}{ll}
\lambda_{\text {disEV }}(t) & \begin{array}{l}
\text { Weight of the portion related to the EV discharge in } \\
\text { period ' } \mathrm{t} \text { ' }
\end{array} \\
\lambda_{\text {grid }}(t) & \begin{array}{l}
\text { Weight of the portion related to the energy required } \\
\text { from the grid in period ' } \mathrm{t} \text { ' }
\end{array} \\
\lambda_{\text {sold }}(t) & \begin{array}{l}
\text { Weight of the portion related to energy sold to the grid } \\
\text { in period ' } \mathrm{t} \text { ' }
\end{array}
\end{array}
$$

\section{INTRODUCTION}

The reduction of energy storage costs is opening new markets previously considered unfeasible in the energy industry. The integration of intelligent residential photovoltaic (PV) inverters and sizable battery systems originated a new class of device, called residential energy storage system [1]. The integration of PV and storage is a natural progression of technologies to reduce electricity costs because inverter sharing allows consumers to avoid the expenses of a second inverter to the battery system. Although most PV production facilities operate without storage, there are potential benefits of the use of energy storage. The main benefit to consumers is suggested to lie in its economics. This is achieved by buying and storing electricity during periods of lower demand, when prices are lower, or by storing the excess energy produced by the PV production. This stored energy is then used at peak periods when energy is more expensive, reducing the consumer demand.

Efficient scheduling of charge and discharge of the battery is essential to maximize the amount of energy produced by PV production and minimize the cost of energy consumed. Electric Vehicles (EVs) have been gaining more importance, namely contributing to the electrification of the transportation sector, which is a major fossil fuel consumer [2]. EVs have challenges and opportunities that should be examined in detail. The energy requirements of an EV load can be compared to a small residence. Moreover, the EV can also be used as a resource, especially during peak periods with the possibility of operating in vehicle-to-home (V2H) and vehicle-to-grid (V2G) modes.

One way to induce consumers to shift the energy consumption of peak periods to off-peak periods is through tariffs which vary according to the time. In Portugal Time-ofUse (ToU) tariffs are available, in which the tariffing scheme is divided into up to four periods during the day, and in each of these periods the energy price is different. Another rate for the same purpose is the Day-Ahead Pricing (DAP), where the price of energy varies every hour and consumers are informed one day in advance. In countries like the United States and Spain this rate is already available. However, it is unconceivable for consumers to keep track of hourly prices to manually program their devices. Therefore, an energy management system to support automatic decision is necessary to define the periods in which it is advantageous to consume the electricity from the network, PV or from the energy storage system [3]. However, to keep the system cost low, a light and efficient optimization/control system is advocate as the processing power is usually low.
The organization of the paper is as follows: in Section 2, a brief literature review and paper contributions are highlighted; Section 3 presents the methodology, the mathematical model, and the differential evolution algorithm used proposed support system. Then, in Section 4 the case study description is introduced; Section 5 presents the results and discussion and finally, in Section 6, the conclusions are exposed.

\section{RESIDENTIAL ENERGY MANAGEMENT SYSTEM}

In this section a brief literature overview of residential energy management is conducted. In addition, the main contributions of the paper are provided.

\section{A. Literature Overview}

There are several recent studies on home energy management, involving PV production, energy storage systems and electric vehicles.

The work done by [4] presents a demand side management (DSM) to manage residential load on an intermittent supply grid situation, coordinating components such as the grid, solar panels, battery bank and load demand. In this study, even with high amounts of drops in power supply with DSM was possible to ensure energy supply throughout the day. It was also possible a reduction in the size of the installation of solar panels and batteries, reducing the cost of the backup system. The study [5] proposed an energy management system that combines DSM strategies to minimize the cost to the consumer and to reduce the consumption of the grid. This was accomplished by scheduling the household appliances, the use of solar panels, and a storage system under a ToU tariff.

The work [6] presents a methodology for the design of a PV system and energy storage for a smart home. The load profile of the same is affected by the energy management system that operates under a Demand Response (DR) based on dynamic price. The energy management system considers a PV installation of small scale, an electric vehicle with an operating capacity in $\mathrm{V} 2 \mathrm{H}$ and $\mathrm{V} 2 \mathrm{G}$ modes and an energy storage system. In [7] an optimization model for scheduling the operation of home appliances was proposed. The model considers a ToU tariff, PV production and an electric vehicle that is always connected to the house and has operating capacity in V2H mode.

In [8] an energy management system is developed considering smart appliances, an electric vehicle, and a dynamic price for electricity. The system does the scheduling of operating periods of the appliances and EV charging. But it is not considered the ability to operate the vehicle in $\mathrm{V} 2 \mathrm{H}$ and V2G modes. In [9], a novel agent-based model to address the long-term scheduling of distributed energy resources is proposed. The long-term problem is split into small time windows that can be effectively solved sequentially by off-theshelf deterministic approaches, but optimality is not guaranteed. In work [10] is shown an energy management system based on predictive control that considers uncertainties in energy production forecasting, consumption and price. The system includes smart appliances, an energy storage system, 
electric vehicle capable of operating in $\mathrm{V} 2 \mathrm{H}$ mode and a cogeneration unit (CHP). The study [1] contains an economic analysis of energy billing considering different rates available in California and the use or not of PV production and batteries for energy storage.

The study [11] proposes a robust approach to dealing with the uncertainty of photovoltaic power generation for the load scheduling of a smart home. It is considered the PV production, an electric vehicle and a real-time rate for the purchase of energy. In [12] an investigation of a home energy management system with DR strategies based on dynamic pricing and peak power limitation is performed. The study considers a small scale distributed PV production, an electric vehicle with an operating capacity in $\mathrm{V} 2 \mathrm{H}$ and $\mathrm{V} 2 \mathrm{G}$ modes and an electric energy storage system. In [13] it was made a DSM system to optimize the programming of a small-scale PV system and a storage system. A ToU rate was used and a model was developed to reduce the cost of electricity to the consumer. In [14] a demonstration is done in hardware of an energy management system. Such a system considers a PV small scale production, a storage system and a DR strategy based on dynamic price. The work [15] presents a methodology for the design of a PV and energy storage system for a smart home. The energy management system includes a DR strategy, a PV installation of small scale and an energy storage system.

\section{B. Contributions of this work}

This work proposes the development of an energy management system in order to support the automatic decision that considers the load of a residence, a PV production, a residential energy storage system, and an electric vehicle with capacity of operating in V2H and V2G modes. The system was implemented to be able to operate with different tariff modes, namely, simple rate, bi-hourly rate and DAP rate. The goal of management is to reduce the cost of energy for the consumer. For the development of the home energy management system a control function is proposed, as well as the grid, battery and EV constraints. For each tariff mode 8 scenarios were evaluated with summer and winter profiles. The use of a differential evolution (DE) algorithm is proposed to adjust the objective function for the online control system.

\section{Methodology}

In this section, it is explained how the problem was modeled and combined with the use of $\mathrm{DE}$ algorithm to perform the management of the energy devices in the residential house.

\section{A. Online energy devices control}

The management system regulates the operation of the charge and discharge process for the battery and the electric vehicle as well as the energy that is bought and sold to the network to obtain the lowest energy cost for the user. Fig. 1. shows a diagram of the energy management problem model. The advantage of this model is that it requires very few processing power (lightweight implementation) to decide whether to charge/discharge EV or battery and import/export energy. However, the system is deciding for the instant moment without much information of the future. This means that the daily overall optimal solution is not achieved. Therefore, some modifications are introduced in the control function to improve its ability to find better online solutions depending on the house context. These weights are optimized offline according to forecast data.

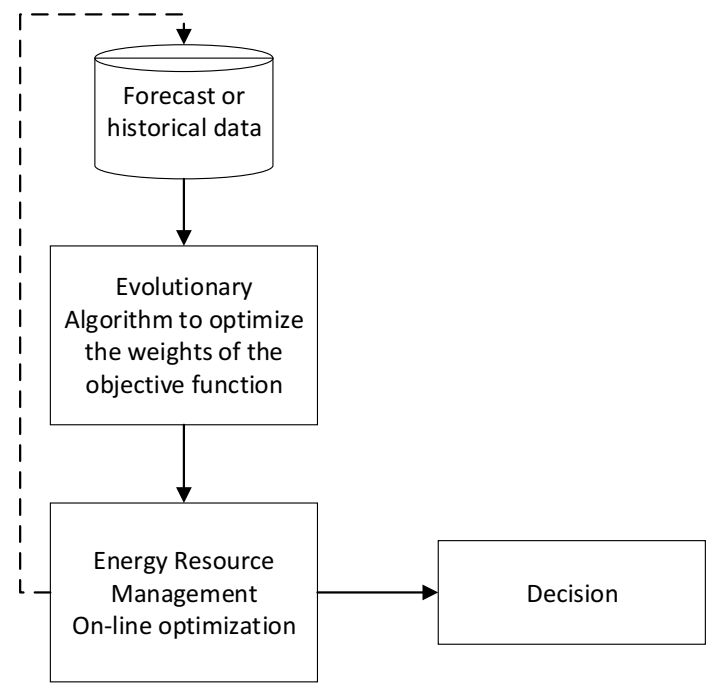

Figure 1. Diagram of the energy resource management model

\section{Control objective function}

$$
\begin{aligned}
& \text { Minimize } E= \\
& \left(\begin{array}{c}
P_{\text {grid }}(t) \cdot \lambda_{\text {grid }}(t)+P_{\text {disB }}(t) \cdot \lambda_{\text {disB }}(t)+ \\
P_{\text {disEV }}(t) \cdot \lambda_{\text {dissV }}(t)-P_{\text {chB }}(t) \cdot \lambda_{\text {chB }}(t)- \\
P_{\text {chEV }}(t) \cdot \lambda_{\text {chEV }}(t)-P_{\text {sold }}(t) \cdot \lambda_{\text {sold }}
\end{array}\right) \Delta t
\end{aligned}
$$

where $\lambda$ is a weight parameter of the control system used for tuning the decision variables. These weights are optimized by $\mathrm{DE}$ in offline mode. Each weight influences if the energy device should be used or kept for later use during the day. The control decision is made for each period $t$.

\section{Problem constraints}

The restrictions of the problem are as follows. Equation (2) represents the power balance of the system in each moment $t$. The power drawn from the grid is limited by the maximum contract. Constraints (4) and (5) ensures that the power requested from, and sold to the grid is never negative.

$$
\begin{gathered}
P_{\text {grid }}(t)+P_{\text {pv }}(t)+P_{\text {disB }}(t)+P_{\text {disEV }}(t)- \\
P_{\text {load }}(t)-P_{\text {chB }}(t)-P_{\text {chEV }}(t)-P_{\text {sold }}(t)=0 \\
P_{\text {grid }}(t) \leq P_{\text {grid }}^{\max } \\
P_{\text {grid }}(t) \geq 0 \\
P_{\text {sold }}(t) \geq 0
\end{gathered}
$$


The constraints (6)-(12) concern the residential battery. Equation (6) limits the battery charging power. Similarly, (7) limits the battery discharge power. Constraints (8) and (9) ensures that the charge and discharge power of the battery are non-negative. Equation (10) limits the amount of energy that can be stored in the battery, and (11) limits the amount of energy that can be drawn from the battery, preventing a deep discharge. Equation (12) prevents the battery from being charged and discharged at the same time.

$$
\begin{gathered}
P_{c h B}(t)-P_{B}^{\max } \cdot X_{c h B}(t) \leq 0 \\
P_{d i s B}(t)-P_{B}^{\max } \cdot X_{\text {dis } B}(t) \leq 0 \\
P_{c h B}(t) \geq 0 \\
P_{d i s B}(t) \geq 0 \\
P_{c h B}(t) \cdot \Delta t \cdot B C E \leq E_{B}^{\text {max }}-E_{B}^{\text {init }}(t) \\
P_{c h B}(t) \cdot \Delta t \leq\left[E_{B}^{\text {init }}(t)-E_{B}^{\text {min }}\right] \cdot X_{\text {disB }}(t) \cdot B D E \\
X_{c h B}(t)+X_{d i s B}(t) \leq 1
\end{gathered}
$$

The constraints (13)-(20) concern the EV. Equation (13) limits the EV charge power. Similarly, (14) limits the EV discharge power. Constraints (15) and (16) ensures that the charge and discharge power of the EV are non-negative. Equation (17) limits the amount of energy that can be stored in the EV, and (18) ensures that the EV has a minimal amount of energy at the end of each period to meet the needs of the user. Equation (19) limits the amount of energy that can be drawn from the EV, preventing a deep discharge. Equation (20) prevents the EV from being charged and discharged at the same time or when the vehicle is absent.

$$
\begin{gathered}
P_{c h E V}(t)-P_{E V}^{\max } \cdot X_{c h E V}(t) \leq 0 \\
P_{d i s E V}(t)-P_{E V}^{\max } \cdot X_{d i s E V}(t) \leq 0 \\
P_{c h E V}(t) \geq 0 \\
P_{\text {disEV }}(t) \geq 0 \\
P_{c h E V}(t) \cdot \Delta t \cdot E V C E \leq E_{E V}^{\max }-E_{E V}^{\text {init }}(t) \\
P_{c h E V}(t) \cdot \Delta t \cdot E V C E+E_{E V}^{\text {init }}(t) \geq E_{E V}^{\text {min }}(t) \\
P_{\text {disEV }}(t) \cdot \Delta t \leq\left[E_{E V}^{\text {init }}(t)-E_{E V}^{\text {min }}(t)\right] \cdot X_{\text {disEV }}(t) \cdot E V D E \\
X_{a b s E V}(t)+X_{c h E V}(t)+X_{\text {disEV }}(t) \leq 1
\end{gathered}
$$

\section{B. Offline Differential Evolution Optimization}

Differential Evolution (DE) is a search strategy used to optimize any given multi-dimensional function $f\left(x_{1}, x_{2}, \ldots, x_{D}\right)$, where $D$ is the number of variables (i.e., the dimension of the problem). The basic version of DE uses a population (Pop) of individuals $\vec{x}_{i, G}=\left[x_{1, i, G} ; \ldots ; x_{D, i, G}\right]$, where $G$ is the generation number, and $i=[1, \ldots, N P]$ is the number of individuals in the population. DE iterates by creating new offspring using mutation and recombination operators. Then, it selects the ones with better fitness (e.g., evaluating them in an objective function) replacing the worst individuals in Pop. The process is repeated for a fixed number of generations (GEN) until a computational condition is reached [16].

\section{Encoding of the Individuals}

To this problem, the solutions are encoded as a matrix $X_{i}^{T \times W}$, where $T$ is the number of periods to optimize, and $W$ is the number of variables, i.e. the number of $\lambda$ weights in Eq. (1). Therefore, an individual $X_{i}$ has a dimension $D=T^{*} W$. The elements from $X_{i}$ are defined as continuous values in the range $[-1,1]$ since the basic version of DE was originally designed to work with continuous variables. The values are then mapped into the interval [-inf,+inf] before replacing in the objective function using the follow equation:

$$
\lambda=f(x)=\tan \left(x * \frac{\pi}{2}\right)
$$

With the help of this function, all the values in individual $X_{i}$ can be mapped into the range [-inf,+inf], with $f(-1) \rightarrow-$ inf and $f(1) \rightarrow+$ inf.

\section{Initialization}

Each decision variable in every matrix-individual of the initial population is assigned a randomly chosen value from the boundary constraints:

$$
X_{i}^{n, m}=\operatorname{rand}_{i}^{n, m}[-1,1]
$$

where $\operatorname{rand}_{n, m}$ denotes a random uniformly distributed value in the range $[-1,1]$ for each decision variable.

\section{Mutation}

For each target individual $X_{i, G}$, a mutant vector $M_{i, G+1}$ is generated according to the following equation:

$$
M_{i, G+1}=X_{r 1, G+1}+F\left(X_{r 2, G+1}-X_{r 3, G+1}\right)
$$

where $r 1 \neq r 2 \neq r 3 \neq i \in\{1,2, \ldots, N P\}$ are randomly chosen indices from the population mutually different from each other and from the current target vector $i$, and $F$ is a real number to scale the difference vector $\left(X_{r 2, G+1}-X_{r 3, G+1}\right)$.

\section{Recombination}

The recombination operator is applied to create the trial 
vector $T r_{i, G+1}$ according to:

$$
\begin{aligned}
& \operatorname{Tr}_{i, G+1} \\
& =\left\{\begin{array}{lc}
M_{i, G+1} & \text { if }\left(\operatorname{rand}_{i}^{n, m}[0,1]<C r \vee(j=\mathrm{Rnd})\right. \\
X_{i, G} & \text { otherwise }
\end{array}\right.
\end{aligned}
$$

where $\mathrm{Cr}$ represents the probability of choosing the $j$ th element of $M_{i, G+1}$ otherwise from $X_{i, G}$. A random integer value Rnd is chosen in the interval $[1, D]$ to guarantee that at least one element is taken from $M_{i, G+1}$.

\section{Boundary Constraints}

In this work, we applied a simple reinitialization boundary control as follows:

$$
\operatorname{Tr}_{i, G+1}^{n, m}=\operatorname{rand}_{i}^{n, m}[-1,1] \text { if } \operatorname{Tr}_{i, G+1}^{n, m}<-1 \vee \operatorname{Tr}_{i, G+1}^{n, m}>1
$$

This boundary control method showed to be effective for

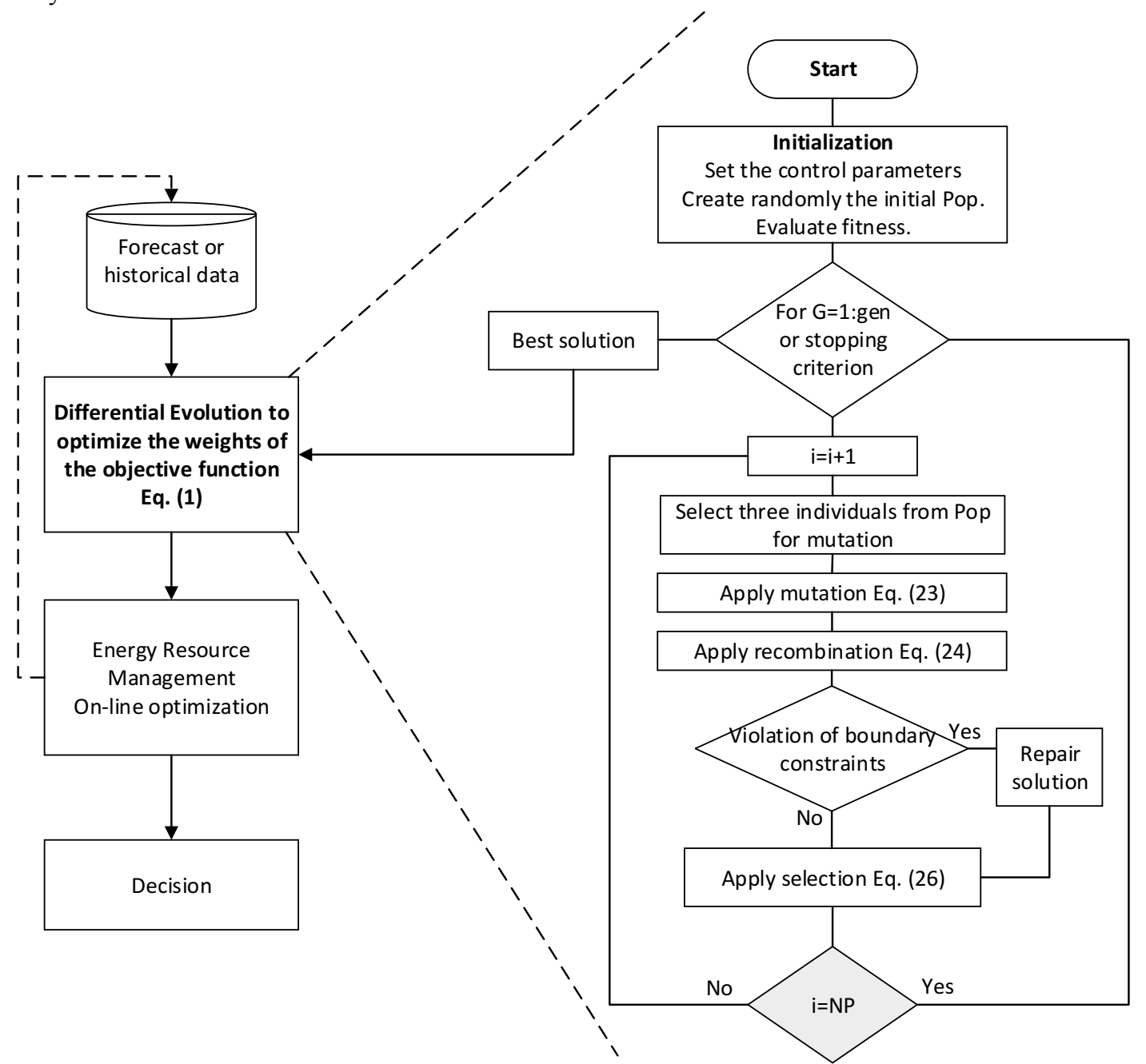

Figure 2. Differential evolution algorithm the application studied in this paper. Other repair methods can be analyzed in future work.

\section{Fitness and Selection}

Selection follows a simple rule of elitist done by comparing the fitness between the trial matrix $T r_{i, G+1}^{n, m}$, and the target matrix $X_{i, G}$ in the objective function:

$$
\operatorname{Pop}_{i, G+1}=\left\{\begin{array}{lc}
\operatorname{Tr}_{i, G+1} & \text { if } f\left(\operatorname{Tr}_{i, G+1}\right) \leq f\left(X_{i, G}\right) \\
X_{i, G} & \text { Otherwise }
\end{array}\right.
$$

where $P_{o p} p_{i, G+1}$ is the next generation population, that changes by accepting or rejecting new individuals, and $f($.$) is the$ fitness function used to measure the performance of an individual (i.e., Eq. (1)). A flowchart of DE algorithm is presented in Fig. 2. 


\section{CASe Study}

To prove the energy management system applicability various scenarios were created considering the Portuguese context. For the case study, several combinations of energy resources were made and applied to the three tariffs for a week in January and another in August. The energy devices considered in each scenario is shown in Table I.

TABLE I. RESOURCES IN EACH SCENARIO

\begin{tabular}{ccccc}
\hline \multicolumn{2}{c}{ Scenario } & Battery & PV production & EV \\
\hline \multirow{4}{*}{ No $\boldsymbol{E} \boldsymbol{V}$} & 1 & & & \\
& 2 & $\mathrm{X}$ & & \\
& 3 & & $\mathrm{X}$ & \\
With $\boldsymbol{E} \boldsymbol{V}$ & 4 & $\mathrm{X}$ & $\mathrm{X}$ & \\
& 5 & & & $\mathrm{X}$ \\
& 6 & $\mathrm{X}$ & & $\mathrm{X}$ \\
& 7 & & $\mathrm{X}$ & $\mathrm{X}$ \\
& 8 & $\mathrm{X}$ & $\mathrm{X}$ & $\mathrm{X}$ \\
\hline
\end{tabular}

The consumption data used is from a real Portuguese residence with a single-phase installation of $10.35 \mathrm{kVA}$ with a sampling time of 15 minutes. The household and PV production dataset are available at [17]. The installed capacity of the PV panels considered is $1.2 \mathrm{kWp}$. The residential battery considered was a Tesla Powerwall with storage capacity of 6.4 $\mathrm{kWh}$. Its charge and discharge rate is $3.3 \mathrm{~kW}$ with an efficiency of $94 \%$, while the depth of discharge is $100 \%$. A state of charge of $1.92 \mathrm{kWh}$ at the beginning of the first day was considered, i.e. $30 \%$.

The specifications of a Renault ZOE. The EV has a battery of $22 \mathrm{kWh}$, with a charge and discharge rate of $3 \mathrm{kWh}$ and an efficiency of $90 \%$. The depth of discharge is $80 \%$. In the simulations, it is considered that at the beginning of the first day the EV has $16 \mathrm{kWh}$. The scenarios also consider that the EV leave the house every day at 08:00 and return at 19:00, using around $6 \mathrm{kWh}$ which is equivalent to drive approximately $40 \mathrm{~km}$. The EV needs to be fully charged before leaving every day.

The price of energy used for the single rate was 0.1551 $€ / \mathrm{kWh}$. For the bi-hourly was $0.0926 € / \mathrm{kWh}$ for the off-peak periods and $0.2064 € / \mathrm{kWh}$ for the peak periods (cases without an EV). For the cases with an EV it was used $0.0843 € / \mathrm{kWh}$ for the off-peak and $0.1970 € / \mathrm{kWh}$ for the peak periods. This is an incentive price provided by a Portuguese utility company for consumers with an EV. The prices of electricity used for the DAP rate was taken from the Spanish market that already has this type of tariff and it is called PVPC ${ }^{1}$ (Voluntary Price for the Small Consumer). The sale price of energy to the grid was calculated according to the Portuguese law and the average price considered was $0.0453 € / \mathrm{kWh}$.

\section{RESUlts AND DiscusSiON}

In this section, results are discussed. In table II, the average weekly cost for each scenario are depicted without weight optimization $\lambda$. Regarding cases study 2 and 6 , the single rate energy costs were not evaluated as the use of a battery without a PV system cannot bring an economic benefit. However, with varying energy prices, such as bi-hourly and DAP, the benefits can be measured even without PV.

TABLE II. AVERAGE WEEKLy COST FOR EACH SCENARIO $(\lambda=1)$

\begin{tabular}{ccccc}
\hline \multirow{2}{*}{ Scenario } & \multicolumn{3}{c}{$\begin{array}{c}\text { Tariff } \\
\text { Bi-hourly }\end{array}$} & DAP \\
\hline \multirow{3}{*}{ No $\boldsymbol{E} \boldsymbol{V}$} & 1 & $18.60 €$ & $20.45 €$ & $14.00 €$ \\
& 3 & - & $19.37 €$ & $14.00 €$ \\
& 4 & $15.03 €$ & $15.98 €$ & $11.03 €$ \\
& 5 & $25.84 €$ & $23.30 €$ & $19.14 €$ \\
With $\boldsymbol{E} \boldsymbol{V}$ & 6 & - & $23.30 €$ & $19.14 €$ \\
& 7 & $22.27 €$ & $19.00 €$ & $16.18 €$ \\
& 8 & $20.27 €$ & $19.00 €$ & $16.18 €$ \\
\hline
\end{tabular}

In Table III, the average weekly energy costs over the year for the household simulation are depicted for each scenario using DE optimized weights. Average weekly energy cost for each scenario (optimized weights) is reduced in almost every case when compared to Table II. In scenario 1 results are not improved, i.e. no controllable energy devices (battery, EV and PV) while cost reductions are achieved in scenario 2, 4, 5, 6, 7 and 8 . Noticeable reduction is verified in tariff 2 between and $14 \%$ (scenario 5) and $36 \%$ (scenario 8 ). This is related with the fact that best resource usage can be achieved when there are at least two distinct prices in the tariff (e.g. charge battery during low price periods and use its energy in high price periods). The simple implemented control function is only able to influence this decision adequately with the use of the proposed weights, while still maintain its simplicity and light computational use.

TABLE III. AvERAge WEEKLy COST For EACH SCENARIo (DE $\lambda$ )

\begin{tabular}{ccccc}
\hline \multirow{2}{*}{ Scenario } & \multicolumn{3}{c}{ Tariff } \\
& & Single & Bi-hourly & DAP \\
\hline \multirow{3}{*}{ No $\boldsymbol{E} \boldsymbol{V}$} & 1 & $18.60 €$ & $20.45 €$ & $14.00 €$ \\
& 2 & - & $15.20 €$ & $13.23 €$ \\
& 3 & $15.03 €$ & $15.98 €$ & $11.03 €$ \\
& 4 & $13.48 €$ & $10.80 €$ & $9.61 €$ \\
With $\boldsymbol{E} \boldsymbol{V}$ & 5 & $25.84 €$ & $20.04 €$ & $19.14 €$ \\
& 7 & - & $16.30 €$ & $17.67 €$ \\
& 8 & $22.22 €$ & $15.82 €$ & $15.37 €$ \\
& & &
\end{tabular}


It is realized that under these conditions, scenario 4 presents less energy costs, especially with tariff DAP. Scenario 4 uses battery and PV production but EV is not available. In addition, energy costs almost halved in comparison with base scenario 1 in single tariff, which does not use battery, PV and EV. With an EV, the energy costs increase, except scenario with 7 bihourly tariff when compared with scenario 3 . Scenario 8 with the use of bi-hourly tariff presents the case with less energy costs when an EV is considered in the equation. The results suggest that single tariff is less economical than bi-hourly and DAP when a battery or EV is available.

\section{CONCLUSION}

Residential energy storage systems are still in an early stage. However, the constant advances of this technology are enabling lower costs. One of the major drivers of battery technology is the industry of EVs. These devices are increasingly present in the homes and the integrated management of these technologies can bring many economic benefits to users. The energy management system developed in this paper is a light control implementation for residential systems which do not required heavy computational resources.

The results suggest that the energy management system is able to reduce energy costs, up to $57 \%$ with an EV and up to $53 \%$ without an EV in the Portuguese context. Not only does the PV production helps to reduce costs, but also the battery and EV management contribute to bring costs down, namely when adequate tariff is chosen. The DE optimization in offline mode helps to improve the control decision results up to $36 \%$.

Although the proposed approach is not optimal, yet it is recommended and adequate for cost effective implementations, such as Arduino based controllers, e.g. Raspberry $\mathrm{Pi}$, which can handle these calculations without effort.

\section{REFERENCES}

[1] Lam RK, Tran DH, Yeh H. Economics of Residential Energy Arbitrage in California using a PV system with directly connected Energy Storage 2015:67-70. doi:10.1109/IGESC.2015.7359453.

[2] Su W, Eichi H, Zeng W, Chow M-Y. A Survey on the Electrification of Transportation in a Smart Grid Environment. IEEE Trans Ind Informatics 2012;8:1-10. doi:10.1109/TII.2011.2172454.

[3] Srinivasan D, Venayagamoorthy GK. Guest Editorial Special Issue on "Neural Networks and Learning Systems Applications in Smart Grid.” IEEE Trans Neural Networks Learn Syst 2016;27:1601-3. doi:10.1109/TNNLS.2016.2545560.

[4] Khoury J, Mbayed R, Salloum G, Monmasson E. Predictive demand side management of a residential house under intermittent primary energy source conditions. Energy Build 2016;112:110-20. doi:10.1016/j.enbuild.2015.12.011.

[5] Setlhaolo D, Xia X. Combined residential demand side management strategies with coordination and economic analysis. Int J Electr Power Energy Syst 2016;79:150-60. doi:10.1016/j.ijepes.2016.01.016.

[6] Erdinc O, Paterakis NG, Catalão JPS, Pappi IN, Bakirtzis AG. Smart households and home energy management systems with innovative sizing of distributed generation and storage for customers. Proc Annu Hawaii Int Conf Syst Sci 2015;2015-March:1462-71. doi:10.1109/HICSS.2015.178.

[7] Huang Y, Tian H, Wang L. Demand response for home energy management system. Int J Electr Power Energy Syst 2015;73:448-
55. doi:10.1016/j.ijepes.2015.05.032.

[8] Paterakis NG, Medeiros MF, Catalao JPS, Siaraka A, Bakirtzis AG, Erdinc O. Optimal daily operation of a smart-household under dynamic pricing considering thermostatically and nonthermostatically controllable appliances. Int Conf Power Eng Energy Electr Drives 2015;2015-Septe:389-93. doi:10.1109/PowerEng.2015.7266348.

[9] Lezama F, Palominos J, Rodriguez-Gonzalez AY, Farinelli A, Munoz de Cote E. Agent-Based Microgrid Scheduling: An ICT Perspective. Mob Networks Appl 2017. doi:10.1007/s11036-0170894-X.

[10] Zhang Y, Zhang T, Wang R, Liu Y, Guo B. Optimal operation of a smart residential microgrid based on model predictive control by considering uncertainties and storage impacts. Sol Energy 2015;122:1052-65. doi:10.1016/j.solener.2015.10.027.

[11] Wang C, Zhou Y, Jiao B, Wang Y, Liu W, Wang D. Robust optimization for load scheduling of a smart home with photovoltaic system. Energy Convers Manag 2015;102:247-57. doi:10.1016/j.enconman.2015.01.053.

[12] Erdinc O, Paterakis NG, Mendes TDP, Bakirtzis AG, Catalão JPS. Smart Household Operation Considering Bi-Directional EV and ESS Utilization by Real-Time Pricing-Based DR. IEEE Trans Smart Grid 2015;6:1281-91. doi:10.1109/TSG.2014.2352650.

[13] $\mathrm{Wu} \mathrm{Z}$, Tazvinga $\mathrm{H}$, Xia X. Demand side management of photovoltaic-battery hybrid system. Appl Energy 2015;148:294 304. doi:10.1016/j.apenergy.2015.03.109.

[14] Yao L, Lai C-C, Lim WH. Home Energy Management System Based on Photovoltaic System. 2015 IEEE Int Conf Data Sci Data Intensive Syst 2015:644-50. doi:10.1109/DSDIS.2015.42.

[15] Erdinc O, Paterakis NG, Pappi IN, Bakirtzis AG, Catalão JPS. A new perspective for sizing of distributed generation and energy storage for smart households under demand response. Appl Energy 2015;143:26-37. doi:10.1016/j.apenergy.2015.01.025.

[16] Price, Kenneth, Storn, Rainer M., Lampinen JA. Differential Evolution. Berlin/Heidelberg: Springer-Verlag; 2005. doi:10.1007/3-540-31306-0.

[17] IEEE. Inteligent Data Mining and Analysis Datasets. PSACE-IDMA WG 2016. 